\title{
Dr. V. Balaram (NGRI, Hyderabad), wins two academic awards, Dr. C. V. Raman Memorial Award \& ISMAS Lifetime Achievement Award
}

Dr. V. Balaram, Former Emeritus Scientist, Chief Scientist \& Head, Geochemistry Division, CSIR - National Geophysical Research Institute (NGRI), Hyderabad is a Fellow of the Geological Society of India. He won several national and international awards including S. Narayanaswamy Award in 2010 from the Society, and National Geoscience Award from the government of India in 2000.

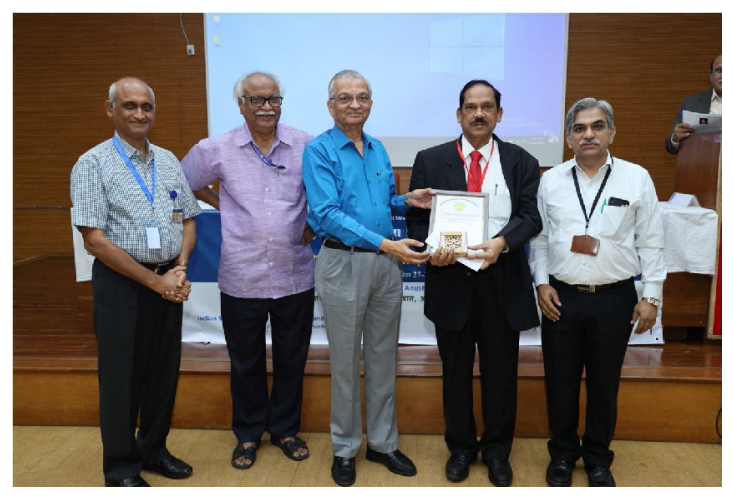

Dr. Anil Kakodkar, Former Chairman, Atomic Energy Commission of India and the Secretary to the Government of India; Director, BARC; and Padma Vibhushan, presented ISMAS Lifetime Achievement Award to Dr. V. Balaram at a Function in Bhabha Atomic Research Center (BARC), Mumbai on $29^{\text {th }}$ November, 2019. The award is given to him for his outstanding contributions in the area of inductively coupled plasma mass spectrometry (ICP-MS) in earth and environmental sciences.

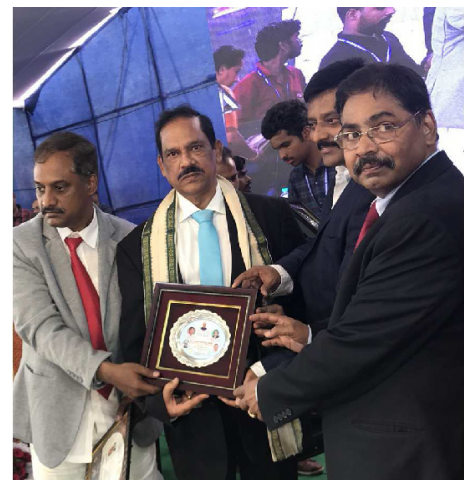

Dr. C. V. Raman Memorial Award was awarded by the Science City of Andhra Pradesh, Amaravati, AP, and presented by Prof. H. Purushottam, Chairman, NRDC, New Delhi; Prof. Hemachandra Reddy, Chairman, APSCHE, Amaravati; and Secretary, Andhra Pradesh Academy of Sciences, Prof. M. Basaveswara Rao, at Andhra Pradesh Science Congress held at Dr. B.R. Ambedkar University, Srikakulam, AP on $28^{\text {th }}$ November, 2019, for his contributions towards science popularization and communications. 